\title{
Radiation-induced vaginal stenosis: current perspectives
}

\author{
This article was published in the following Dove Press journal: \\ International Journal of Women's Health \\ 2 May 2017 \\ Number of times this article has been viewed
}

\section{Lucinda Morris' \\ Viet Do' \\ Jennifer Chard'}

Alison $\mathrm{H} \mathrm{Brand}{ }^{2,3}$

'Crown Princess Mary Cancer Centre

Westmead, Radiation Oncology

Network, Westmead, 'Discipline

of Obstetrics, Gynaecology and

Neonatology, Westmead Clinical

School, University of Sydney,

Camperdown, ${ }^{3}$ Department of

Gynaecological Oncology, Westmead

Hospital, Westmead, NSW, Australia
Correspondence: Alison $\mathrm{H}$ Brand Department of Gynaecological Oncology, Westmead Hospital, PO Box 533, Westmead, NSW 2045, Australia Email alison.brand@health.nsw.gov.au

\begin{abstract}
Treatment of gynecological cancer commonly involves pelvic radiation therapy (RT) and/or brachytherapy. A commonly observed side effect of such treatment is radiation-induced vaginal stenosis (VS). This review analyzed the incidence, pathogenesis, clinical manifestation(s) and assessment and grading of radiation-induced VS. In addition, risk factors, prevention and treatment options and follow-up schedules are also discussed. The limited available literature on many of these aspects suggests that additional studies are required to more precisely determine the best management strategy of this prevalent group after RT.
\end{abstract}

Keywords: gynecological cancer, radiation therapy, vaginal stenosis, brachytherapy, vaginal dilators

\section{Introduction}

Treatment of uterine, cervical, vaginal and anorectal cancers commonly involves pelvic radiation therapy (RT). A commonly observed side effect of pelvic RT is radiationinduced vaginal stenosis (VS), defined as abnormal tightening and shortening of the vagina due to the formation of fibrosis. ${ }^{1,2} \mathrm{VS}$ may occur following external beam radiation therapy (EBRT) or brachytherapy or both delivered in the definitive, adjuvant or palliative setting. It is well recognized that RT-induced VS may have negative impacts on patient well-being, in particular sexual dysfunction and dyspareunia and implications for limiting physical examination in the posttreatment surveillance period.

\section{Incidence of RT-induced VS}

The reported incidence of RT-induced VS is highly variable and may depend on patient, tumor and treatment factors. These factors include site of disease, RT modality, dose, dose fractionation schedule, concurrent chemotherapy and other patient factors including age and inherent radiosensitivity of tissues, and whether the side effect was specifically assessed. The existing data regarding the incidence of VS are largely based on retrospective evidence and small cohorts, and there is a wide variation between investigators in measurement techniques and reported grading of VS. This variation is reflected in the literature, with cited rates of VS ranging from $1.25 \%$ to $88 \% .^{3-5}$ Furthermore, it is noted that in the clinical setting, the discussion of VS and associated sexual dysfunction may be limited due to various issues including age, marital status and cultural factors. Therefore, incidence rates of VS and sexual dysfunction are likely underreported. ${ }^{6}$

Nevertheless, modern data suggest that RT-induced VS is a common toxicity following pelvic RT. In a retrospective study of women with Stage $1 \mathrm{~B}$ to Stage 4 cervical cancer treated with pelvic RT and/or brachytherapy, the prospectively recorded incidence 
of RT-induced VS was reported as $38 \% .^{7}$ Furthermore, it has been reported that VS most commonly occurs within the first year posttreatment. ${ }^{7}$ Another prospective study of 54 patients also reports that VS gradually increases with time, with grade 1 stenosis occurring within the first year of follow-up and the time to occurrence of moderate-to-severe stenosis gradually increasing up to 3 years following treatment. ${ }^{8}$

The incidence seems to be highest in women undergoing definitive treatment for locally advanced cervical cancer. ${ }^{9,10}$ Recent data from the multicenter international EMBRACE trial demonstrated that VS was the most frequently observed vaginal toxicity in women undergoing definitive chemoradiation and brachytherapy. In this study, 630 patients were prospectively assessed for VS every 3 months in the first year following treatment and every 6 months in the second and third year. Grade 2 VS was defined as vaginal shortening/ narrowing interfering with function and grade 3 as complete vaginal obliteration not surgically correctable, according to the Common Terminology Criteria for Adverse Events (CTCAE) v3.0 $0^{11}$ as shown in Table 1. Grade 2 VS occurred in $29 \%$ of patients and grade $\geq 3$ in $3.6 \%$, with the majority occurring within 6 months. ${ }^{9}$ However, several small study series suggest that RT-induced VS may be less likely in the setting of adjuvant treatment for endometrial cancer using vaginal vault brachytherapy. One retrospective study of 54 patients reports no patients with grade $\geq 2$ vaginal toxicity, including stenosis. ${ }^{12}$ Similar data investigating the use of vaginal dilators in 60 patients with a variety of gynecological cancers showed that surgery and adjuvant RT may also predict a lower risk of VS as compared with definitive RT alone. ${ }^{13}$

Although less commonly reported in the literature, VS following pelvic RT for rectal and anal cancer is also recognized. One study reports over two-thirds of women experiencing degree of VS post-RT for anal or rectal tumors. Although the study involved a relatively small cohort of 54 patients, this rate of VS has a plausible radiobiological basis, given the authors report a mean vaginal doses of 50.0 and 36.8 Gy for anal and rectal cancer patients, respectively. ${ }^{14}$ Another larger prospective study investigating rates of VS in 94 female patients with anal squamous cell cancer treated with definitive chemoradiation reported a VS grade distribution of $27.1 \%$ for grade 2 and $37.1 \%$ for grade 3 (as defined by CTCAE v3.0). ${ }^{5,11}$

\section{Pathogenesis}

The vagina is lined by stratified squamous epithelium overlying the lamina propria and longitudinal muscle fibers. Acute RT reactions are defined as those occurring during or immediately after RT. Following either EBRT or brachytherapy, these acute reactions may include mucosal inflammation, hyperemia and epithelial denudation leading to ulceration and endothelial injury causing small-vessel thrombosis, edema and smooth muscle necrosis. ${ }^{15,16}$

Delayed or late RT reactions are defined as those occurring later than 3 months post-RT. VS is considered a late reaction and is due to damage to the vaginal mucosa caused by increased collagen production in the submucosal fibroconnective tissue layer. ${ }^{15}$ This leads to atrophic changes of the vaginal mucosa and obliteration of the muscle and vasculature resulting in hypoxia, tissue atrophy and fibrosis. Clinically, this results in the development of telangiectasia, mucosal pallor, adhesions and occlusion of the vaginal canal, loss of elasticity and fragility of the vaginal wall. ${ }^{15-17}$

\section{Clinical manifestation of RT-induced VS}

RT-induced VS is commonly associated with sexual dysfunction, including dyspareunia and postcoital bleeding. ${ }^{18,19}$ In severe cases, an inability to have intercourse may occur. It is recognized that the severity of the impact of VS may be multifactorial and partly due to other accompanying symptoms and side effects such as vaginal dryness and atrophy due to damage to the epithelium. ${ }^{20}$ These may be further exacerbated by posttreatment ovarian failure or menopausal status resulting in further decreased lubrication and thinning of vaginal tissues. ${ }^{20}$ It has been suggested that VS may also predispose to increased trauma and infection, although the true prevalence of this is not known. ${ }^{15}$

Overall, VS can impact negatively on quality of life and represent a long-term source of psychological and physical distress. ${ }^{20-22}$ RT-induced VS may prevent adequate physical internal examination in the posttreatment follow-up period in order to detect disease recurrence. ${ }^{22}$

Table I Common Terminology Criteria for Adverse Events v3.0 grading for vaginal stenosis

\begin{tabular}{|c|c|c|c|c|c|c|}
\hline Adverse event & Short name & Grade I & Grade 2 & Grade 3 & Grade 4 & Grade 5 \\
\hline Vaginal stenosis/length & Vaginal stenosis & $\begin{array}{l}\text { Vaginal narrowing } \\
\text { and/or shortening not } \\
\text { interfering with function }\end{array}$ & $\begin{array}{l}\text { Vaginal narrowing } \\
\text { and/or shortening } \\
\text { interfering with function }\end{array}$ & $\begin{array}{l}\text { Complete obliteration; } \\
\text { not surgically correctable }\end{array}$ & - & - \\
\hline
\end{tabular}

Note: Data from Common Terminology Criteria for Adverse Events (CTCAE). Version 3.0."' 


\section{Assessment and grading of RT-induced VS}

Several grading systems and methods for assessing VS exist, none of which have been uniformly adopted.

The National Cancer Institute CTCAE v $3.0^{11}$ defines VS as a disorder characterized by the narrowing of the vaginal canal; the corresponding definitions of all grades are outlined in Table 1. This has now been replaced with CTCAE v4.0. ${ }^{23}$ The first three grades of vagina stricture are as follows: grade 1 - "asymptomatic, mild vagina shortening or narrowing," grade 2 - "vaginal narrowing and/or shortening not interfering with physical examination" and grade 3 - "vaginal narrowing and/or shortening interfering with the use of tampons, sexual activity or physical examination."

The Late Effects in Normal Tissues-Subjective, Objective, Management and Analytic Score (LENT SOMA) ${ }^{24,25}$ grading scale for vaginal injury due to radiation and/or chemotherapy is based on the assessment of subjective symptoms, observed clinical features, management strategies required and analytical tests (Figure 1). VS and length is listed as one of the numerous symptoms that may be graded according to this scale.

\section{Risk factors}

Multiple risk factors for the development of RT-induced VS have been identified in the literature. Reported risk factors include patient age, RT dose and volume of vagina treated, combination of EBRT and brachytherapy and tumor extension to the vagina.

Increasing dose and volume of vagina treated is associated with all grades of VS. ${ }^{9,14,26,27}$ In the setting of locally advanced cervical cancer, patients from the EMBRACE study were prospectively assessed to identify risk factors for VS. Factors identified were tumor extension into the vagina at diagnosis, plus an EBRT dose exceeding 45 Gy in 25 fractions and total EBRT and brachytherapy rectovaginal reference point dose. ${ }^{9}$ Similarly, in women treated with image-guided brachytherapy alone for cervical or endometrial cancer, vaginal dose and

VAGINA

\begin{tabular}{|c|c|c|c|c|c|c|}
\hline & Grade 1 & Grade 2 & Grade 3 & Grade 4 & & Scoring \\
\hline $\begin{array}{l}\text { Subjective } \\
\text { Dyspareunia } \\
\text { Dryness } \\
\text { Bleeding } \\
\text { Pain }\end{array}$ & $\begin{array}{l}\text { Occasional and minimal } \\
\text { Occasional } \\
\text { Occasional } \\
\text { Occasional and minimal }\end{array}$ & $\begin{array}{l}\text { Intermittent and tolerable } \\
\text { Intermittent } \\
\text { Intermittent } \\
\text { Intermittent and tolerable }\end{array}$ & $\begin{array}{l}\text { Persistent and intense } \\
\text { Persistent } \\
\text { Persistent } \\
\text { Persistent and intense }\end{array}$ & $\begin{array}{l}\text { Refractory and excruciating } \\
\text { Refractory } \\
\text { Refractory } \\
\text { Refractory and excruciating }\end{array}$ & $\begin{array}{l}- \\
- \\
-\end{array}$ & $\begin{array}{l}\text { Instructions } \\
\text { Score the } 17 \\
\text { SOM } \\
\text { parameters } \\
\text { with 1-4 }\end{array}$ \\
\hline $\begin{array}{l}\text { Objective } \\
\text { Stenosis/length } \\
\text { Dryness } \\
\text { Ulceration/necrosis } \\
\text { Atrophy } \\
\text { Appearance } \\
\text { Synechiae } \\
\text { Bleeding }\end{array}$ & $\begin{array}{l}>2 / 3 \text { normal length } \\
\text { Asymptomatic } \\
\text { Superficial, } \leq 1 \mathrm{~cm}^{2} \\
\text { Patchy } \\
\text { Telangiectasia without } \\
\text { bleeding }\end{array}$ & $\begin{array}{l}1 / 3-2 / 3 \text { normal length } \\
\text { Symptomatic } \\
\text { Superficial, }>1 \mathrm{~cm}^{2} \\
\text { Confluent } \\
\text { Telangiectasia with } \\
\text { gross bleeding } \\
\text { Partial } \\
\text { On contact }\end{array}$ & $\begin{array}{l}<1 / 3 \text { normal length } \\
\text { Secondary dysfunction } \\
\text { Deep ulcer } \\
\text { Nonconfluent } \\
\text { Complete } \\
\text { Intermittent }\end{array}$ & $\begin{array}{l}\text { Obliteration } \\
\text { Fistulae } \\
\text { Diffuse } \\
\text { Persistent }\end{array}$ & $\begin{array}{l}- \\
- \\
- \\
- \\
\end{array}$ & $\begin{array}{l}\text { (Score }=0 \text { if } \\
\text { there are no } \\
\text { toxicities) } \\
\text { Total the } \\
\text { scores and } \\
\text { divide by } 17\end{array}$ \\
\hline $\begin{array}{l}\text { Management } \\
\text { Dyspareunia/pain } \\
\text { Atrophy } \\
\text { Bleeding } \\
\text { Stenosis } \\
\text { Dryness } \\
\text { Ulceration }\end{array}$ & $\begin{array}{l}\text { Occasional nonnarcotic } \\
\text { Occasional hormone } \\
\text { cream } \\
\text { Iron therapy } \\
\text { Occasional dilation } \\
\text { Hormone replacement } \\
\text { Conservative }\end{array}$ & $\begin{array}{l}\text { Regular nonnarcotic } \\
\text { Intermittent hormone } \\
\text { cream } \\
\text { Occasional transfusion } \\
\text { Intermittent dilation } \\
\text { Artificial lubrication } \\
\text { Debridement }\end{array}$ & $\begin{array}{l}\text { Regular narcotic } \\
\text { Regular hormone } \\
\text { cream } \\
\text { Frequent transfusions } \\
\text { Persistent dilation } \\
\mathrm{HBO}_{2}\end{array}$ & $\begin{array}{l}\text { Surgical intervention } \\
\text { Surgical intervention } \\
\text { Surgical reconstruction } \\
\text { Graft, surgical repair }\end{array}$ & $\begin{array}{l}- \\
- \\
- \\
-\end{array}$ & LENT score: \\
\hline $\begin{array}{l}\text { Analytic } \\
\text { MRI } \\
\text { Ultrasound } \\
\text { EUA } \\
\text { Cytology/biopsy }\end{array}$ & \multicolumn{4}{|c|}{$\begin{array}{l}\text { Assessment of wall thickness, sinus and fistula formation } \\
\text { Assessment of wall thickness, sinus and fistula formation } \\
\text { Assessment of wall diameter and length and mucosal surface }\end{array}$} & $\begin{array}{l}\mathrm{Y} / \mathrm{N} \\
\mathrm{Y} / \mathrm{N} \\
\mathrm{Y} / \mathrm{N}\end{array}$ & $\begin{array}{l}\text { Date: } \\
\text { Date: } \\
\text { Date: }\end{array}$ \\
\hline
\end{tabular}

Figure I LENT SOMA grading scale for vaginal injury. Reprinted from Int J Radiat Oncol Biol Phys. 1995;3 I (5): 1049-I09I. LENT SOMA scales for all anatomic sites. ${ }^{25}$ With permission from Elsevier. Copyright (C) 995 Published by Elsevier Inc.

Abbreviations: LENT SOMA, Late Effects in Normal Tissues-Subjective, Objective, Management and Analytic Score; HBO resonance imaging; EUA, examination under anesthesia. 
volume were also associated with an increased risk of VS. ${ }^{26,27}$ It is also demonstrated that in women who underwent pelvic RT for rectal and anal cancer, several RT dose-volume characteristics impacted on VS rates, in particular mean dose to the vagina. ${ }^{14} \mathrm{~A}$ higher prescribed dose is also reported to be associated with an increased incidence of VS in women treated with definitive chemoradiation for anal cancer. ${ }^{5}$ Despite limited evidence and available process in assessing vaginal morbidity so far, a dose-volume or a dose-surface concept for treatment planning and reporting is recommended in the International Commission on Radiation Units (ICRU) No 89. ${ }^{28}$

In terms of patient factors, age $>50$ years has been associated with an increased risk of VS in patients treated with pelvic and/or vaginal RT for cervix cancer. ${ }^{7}$ Pallor reaction of vaginal tissues has also been proposed as a predisposing factor for late VS as both have a pathophysiological basis related to mucosal thinning and dryness, atrophy, inflammation and fibrosis. ${ }^{8,29}$ An assessment of grade 2 vaginal pallor reaction at 6 months was reported as predictive of late VS of grades 2 and 3 at 3 years after treatment with high-dose rate brachytherapy for cervical cancer. ${ }^{8}$ Cigarette smoking has also been proposed as a possible patient-related factor predisposing to VS. ${ }^{6}$ This is certainly plausible given the widely recognized synergistic effect of cigarette smoking and late radiation effects on normal mucosal tissues of the aerodigestive tract observed in a number of tumor sites including cervical, lung and head and neck cancer. ${ }^{30-32}$

\section{Prevention strategies and outcomes Vaginal dilatation}

The rationale for vaginal dilatation is to stretch the vaginal mucosa and break down adhesions to maintain vaginal patency. ${ }^{33}$ A concurrent or alternative strategy is to also encourage regular sexual intercourse.

A recent Cochrane review concluded that there is no reliable high-level evidence to show that regular vaginal dilatation prevents radiation-induced VS. ${ }^{22}$ However, observational data indicate that regular use of dilator following RT is associated with lower rates of self-reported VS. ${ }^{34-36}$ Further clinical trials are ideally needed; however, the difficulties of designing appropriate trials to establish a causal relationship are widely acknowledged. ${ }^{1,22}$ There is no evidence to support the use of dilators during RT, which in fact may be harmful. ${ }^{22}$

Despite a lack of high-level evidence, vaginal dilators are continued to be used widely in clinical practice as an accepted prevention strategy for VS. ${ }^{22,37}$ Numerous international reviews and guidelines recommend the use of dilators. ${ }^{22,33,38-40}$
However, no single approach to using vaginal dilator is uniformly utilized, and advice about when and how dilators should be used is highly variable. There is a lack of consensus on multiple aspects of using dilator including the frequency and duration of dilator use, the appropriate time interval following RT in which to commence use, size of dilator, insertion technique and the necessity of dilators in sexually active patients..$^{22,33,38,39}$ The primary site of disease and the RT modality used also impact on whether clinicians advised the use of vaginal dilators. ${ }^{2,37}$

It is recognized that there may be poor compliance with vaginal dilatation due to psychological distress and a lack of consistent or adequate information regarding dilator use. ${ }^{41}$ Educational interventions may improve patient compliance with vaginal dilatation and reduce emotional distress. ${ }^{13}$ A recent Delphi consensus among professional experts concluded that information about dilators should be provided by a radiation oncologist prior to the commencement of treatment, and preferably, a specifically trained oncology nurse should provide the ongoing practical and psychological support. ${ }^{1}$ The panel recommended that dilator use should commence 4 weeks post-RT, be two to three times per week for 1-3 minutes and continue for 9-12 months and that plastic dilator sets are the most appropriate devices. ${ }^{1}$

\section{Topical therapies}

Given that many women discontinue to use dilators before the recommended time, or never start or use less frequently than prescribed due to discomfort with, or dislike of, the dilators, other methods to maintain vaginal patency should be explored.

It has been postulated that the application of local estrogen or benzydamine to treat acute radiation-related changes may prevent the development of later vaginal complications such as VS via the promotion of epithelial regeneration and anti-inflammatory effects. ${ }^{6}$ There have been a small number of studies assessing such topical therapies. ${ }^{42-45}$ One study ${ }^{43}$ showed outcome improvement with the use of vaginal estrogen applications in acute and late toxicity. In particular, the vaginal estrogen-treated patients (in comparison with the controls) had significantly less dyspareunia and few alterations in the vaginal epithelium and vaginal narrowing. ${ }^{43}$ However, these conclusions have limitations in trial design (method of allocation concealment not stated, no quality of life assessment) and outcome reporting (no duration of response reported), emphasizing the need for more contemporary studies to be conducted with improved designs to evaluate the efficacy of these topical treatments. ${ }^{6}$ 
Preliminary analysis of another study ${ }^{46}$ showed that vaginal application of $\alpha$-tocopherol reduces vaginal toxicity and pain, although it does not seem to affect the fibrosis secondary to the effects of long-term RT.

\section{Technical factor}

In cervical cancer management, a pilot study ${ }^{47}$ has shown that by reducing dwell times in vaginal sources (ring and ovoids) and increasing them in tandem/or needles, the dose to vagina and ICRU rectal point can be decreased while maintaining the same dose to the high-risk clinical target volume. Application of this method of vaginal dose deduction is expected to reduce the development of VS and hence contribute toward the prevention of sexual dysfunction in women with cervical cancer.

In endometrial cancer, the use of brachytherapy alone after hysterectomy has increased over time in all women with Stage 1 and in those with high-intermediate-risk disease. ${ }^{48}$ However, given the high rate of successful salvage for patients who develop vaginal recurrence, and the high risk of morbidity from adjuvant radiotherapy, questions arise as to the alternative strategy of observation after surgery in the low- and high-intermediate-risk patients, who are the majority affected with endometrial cancer. ${ }^{49}$

\section{Follow-up and treatment Patient education}

- Patients should be advised at the outset of treatment about the risk of VS and its consequences with regard to sexual function and posttreatment surveillance.

- Practical advice about using vaginal dilator should be provided by a trained member of treatment team.

- Psychosocial support and education should be provided if RT-induced VS occurs.

\section{Clinical assessment}

Vaginal morbidity should be assessed at baseline, 3 monthly for first 2 years and then 6 monthly for subsequent 3 years until discharge from ongoing surveillance. As discussed previously, various grading systems exist for reporting purposes. We note that the recent EMBRACE study used CTCAE v3.0 for the purpose of monitoring VS.

In an ideal world, baseline sexual function should be established pretreatment and reassessed in the posttreatment follow-up period. However, resources and patient interest in this aspect of their care may be lacking as they come to terms with a recent diagnosis of cancer. Nevertheless, patient education regarding VS is part of the care that should be provided by radiation oncologists who treat women with gynecological, anal and rectal cancers.

\section{Conclusion}

Radiation-induced VS is a commonly observed side effect following treatment with pelvic RT for uterine, cervical, vaginal and anorectal cancers. Survivorship care should prioritize and recognize the potential negative impact of VS on the physical and psychological well-being of patients. However, there is a paucity of high-level evidence of the prevention and management strategies for VS, and more up-to-date empirical data are required. In clinical practice, vaginal dilatation remains an internationally accepted prevention strategy for radiation-induced VS. However, no single approach to using vaginal dilator is uniformly recognized, and expert consensus about this issue remains an area of continued need. Nevertheless, it has been strongly recommended that patients receive specialist education about VS at the outset of treatment. Importantly, ongoing psychosocial support and practical advice about VS and regular assessment of vaginal morbidity should be provided in the posttreatment surveillance period.

\section{Disclosure}

The authors report no conflicts of interest in this work.

\section{References}

1. Bakker RM, ter Kuile MM, Vermeer WM, et al. Sexual rehabilitation after pelvic radiotherapy and vaginal dilator use: consensus using the Delphi method. Int J Gynecol Cancer. 2014;24(8):1499-1506.

2. Lancaster L. Preventing vaginal stenosis after brachytherapy for gynaecological cancer: an overview of Australian practices. Eur J Oncol Nurs. 2004;8(1):30-39.

3. Eltabbakh GH, Piver MS, Hempling RE, Shin KH. Excellent long-term survival and absence of vaginal recurrences in 332 patients with low-risk stage I endometrial adenocarcinoma treated with hysterectomy and vaginal brachytherapy without formal staging lymph node sampling: report of a prospective trial. Int J Radiat Oncol Biol Phys. 1997;38(2):373-380.

4. Hartman P, Diddle AW. Vaginal stenosis following irradiation therapy for carcinoma of the cervix uteri. Cancer. 1972;30(2):426-429.

5. Mirabeau-Beale K, Hong TS, Niemierko A, et al. Clinical and treatment factors associated with vaginal stenosis after definitive chemoradiation for anal canal cancer. Pract Radiat Oncol. 2015;5(3):e113-e118.

6. Denton AS, Maher EJ. Interventions for the physical aspects of sexual dysfunction in women following pelvic radiotherapy. Cochrane Database Syst Rev. 2003;(1):CD003750.

7. Brand AH, Bull CA, Cakir B. Vaginal stenosis in patients treated with radiotherapy for carcinoma of the cervix. Int $J$ Gynecol Cancer. 2006;16(1):288-293.

8. Yoshida K, Yamazaki H, Nakamura S, et al. Role of vaginal pallor reaction in predicting late vaginal stenosis after high-dose-rate brachytherapy in treatment-naive patients with cervical cancer. J Gynecol Oncol. 2015; 26(3):179-184.

9. Kirchheiner K, Nout RA, Lindegaard JC, et al. Dose-effect relationship and risk factors for vaginal stenosis after definitive radio(chemo)therapy with image-guided brachytherapy for locally advanced cervical cancer in the EMBRACE study. Radiother Oncol. 2016;118(1):160-166. 
10. Jensen PT, Groenvold M, Klee MC, Thranov I, Petersen MA, Machin D. Longitudinal study of sexual function and vaginal changes after radiotherapy for cervical cancer. Int J Radiat Oncol Biol Phys. 2003;56(4): 937-949.

11. Cancer Therapy Evaluation Program. Common Terminology Criteria for Adverse Events (CTCAE). Version 3.0, DCTD, NCI, NIH, DHHS. 2006. Available from: https://ctep.cancer.gov/protocolDevelopment/ electronic_applications/docs/ctcaev3.pdf. Accessed February 11, 2017.

12. Townamchai K, Lee L, Viswanathan AN. A novel low dose fractionation regimen for adjuvant vaginal brachytherapy in early stage endometrioid endometrial cancer. Gynecol Oncol. 2012;127(2):351-355.

13. Brand AH, Do V, Stenlake A. Can an educational intervention improve compliance with vaginal dilator use in patients treated with radiation for a gynecological malignancy? Int J Gynecol Cancer. 2012;22(5): 897-904.

14. Son $\mathrm{CH}$, Law E, Oh JH, et al. Dosimetric predictors of radiation-induced vaginal stenosis after pelvic radiation therapy for rectal and anal cancer. Int J Radiat Oncol Biol Phys. 2015;92(3):548-554.

15. Grigsby PW, Russell A, Bruner D, et al. Late injury of cancer therapy on the female reproductive tract. Int J Radiat Oncol Biol Phys. 1995;31(5): 1281-1299.

16. Kirchheiner K, Fidarova E, Nout RA, et al. Radiation-induced morphological changes in the vagina. Strahlenther Onkol. 2012;188(11): 1010-1017.

17. Fajardo LF. The pathology of ionizing radiation as defined by morphologic patterns. Acta Oncol. 2005;44(1):13-22.

18. Abbott-Anderson K, Kwekkeboom KL. A systematic review of sexual concerns reported by gynecological cancer survivors. Gynecol Oncol. 2012;124(3):477-489.

19. Lindau ST, Gavrilova N, Anderson D. Sexual morbidity in very long term survivors of vaginal and cervical cancer: a comparison to national norms. Gynecol Oncol. 2007;106(2):413-418.

20. Denton AS, Bond SJ, Matthews S, Bentzen SM, Maher EJ; UK Link Gynaecology-Oncology Group. National audit of the management and outcome of carcinoma of the cervix treated with radiotherapy in 1993. Clin Oncol (R Coll Radiol). 2000;12(6):347-353.

21. Juraskova I, Butow P, Robertson R, Sharpe L, McLeod C, Hacker N. Post-treatment sexual adjustment following cervical and endometrial cancer: a qualitative insight. Psychooncology. 2003;12(3):267-279.

22. Miles T, Johnson N. Vaginal dilator therapy for women receiving pelvic radiotherapy. Cochrane Database Syst Rev. 2014;(9):CD007291.

23. Cancer Therapy Evaluation Program. Common Terminology Criteria for Adverse Events (CTCAE). Version 4.3, DCTC, NCI, NIH, DHHS. 2009 Available from: https://evs.nci.nih.gov/ftp1/CTCAE/ CTCAE_4.03_2010-06-14_QuickReference_8.5x11.pdf. Accessed February 11, 2017.

24. LENT SOMA tables. Radiother Oncol. 1995;35(1):17-60.

25. LENT SOMA scales for all anatomic sites. Int J Radiat Oncol Biol Phys. 1995;31(5):1049-1091.

26. Susko M, Craciunescu O, Meltsner $\mathrm{S}$, et al. Vaginal dose is associated with toxicity in image guided tandem ring or ovoid-based brachytherapy. Int J Radiat Oncol Biol Phys. 2016;94(5):1099-1105.

27. Park HS, Ratner ES, Lucarelli L, Polizzi S, Higgins SA, Damast S. Predictors of vaginal stenosis after intravaginal high-dose-rate brachytherapy for endometrial carcinoma. Brachytherapy. 2015;14(4):464-470.

28. ICRU report 89 , prescribing, recording, and reporting brachytherapy for cancer of the cervix. 2016. Available from: http://www.icru.org/ content/reports/prescribing-recording-and-reporting-brachytherapyfor-cancer-of-the-cervix-report-no-89. Accessed February 11, 2017.

29. Yoshida K, Yamazaki H, Nakamura S, et al. Comparisons of late vaginal mucosal reactions between interstitial and conventional intracavitary brachytherapy in patients with gynecological cancer: speculation on the relation between pallor reaction and stenosis. Anticancer Res. 2013;33(9):3963-3968.

30. Eifel PJ, Jhingran A, Bodurka DC, Levenback C, Thames H. Correlation of smoking history and other patient characteristics with major complications of pelvic radiation therapy for cervical cancer. J Clin Oncol. 2002;20(17):3651-3657.
31. Videtic GM, Stitt LW, Dar AR, et al. Continued cigarette smoking by patients receiving concurrent chemoradiotherapy for limited-stage small-cell lung cancer is associated with decreased survival. $J$ Clin Oncol. 2003;21(8):1544-1549.

32. Browman GP, Wong G, Hodson I, et al. Influence of cigarette smoking on the efficacy of radiation therapy in head and neck cancer. $N$ Engl J Med. 1993;328(3):159-163.

33. International Clinical Guideline Group, National Forum of Gynaecological Oncology Nurses, UK. International Guidelines on Vaginal Dilation After Pelvic Radiotherapy. Oxon: Owen Mumford; 2012.

34. Law E, Kelvin JF, Thom B, et al. Prospective study of vaginal dilator use adherence and efficacy following radiotherapy. Radiother Oncol. 2015;116(1):149-155.

35. Gondi V, Bentzen SM, Sklenar KL, et al. Severe late toxicities following concomitant chemoradiotherapy compared to radiotherapy alone in cervical cancer: an inter-era analysis. Int J Radiat Oncol Biol Phys. 2012;84(4):973-982.

36. Bahng AY, Dagan A, Bruner DW, Lin LL. Determination of prognostic factors for vaginal mucosal toxicity associated with intravaginal highdose rate brachytherapy in patients with endometrial cancer. Int $J$ Radiat Oncol Biol Phys. 2012;82(2):667-673.

37. White ID, Faithfull S. Vaginal dilation associated with pelvic radiotherapy: a UK survey of current practice. Int J Gynecol Cancer. 2006;16(3): $1140-1146$.

38. Sydney Gynaecological Oncology Group. Vaginal dilator therapy: guidelines for the use of vaginal dilators in women receiving pelvic radiotherapy and brachytherapy treatments. Sydney Local Health District; 2012. Available from: http://www.slhd.nsw.gov.au/services/ sgog/VD_Therapy.html. Accessed February 11, 2017.

39. Cancer Institute NSW. EviQ. Supporting document - management of radiation induced vaginal stenosis. 2016. Available from: https://www.eviq.org.au/Protocol/tabid/66/categoryid/180/id/1867/ Supporting+Document +-+ Management + of + Radiation+Induced + Vag inal+Stenosis.aspx. Accessed February 11, 2017.

40. Wilmoth MC, Spinelli A. Sexual implications of gynecologic cancer treatments. J Obstet Gynecol Neonatal Nurs. 2000;29(4):413-421.

41. Cullen K, Fergus K, Dasgupta T, Fitch M, Doyle C, Adams L. From "sex toy" to intrusive imposition: a qualitative examination of women's experiences with vaginal dilator use following treatment for gynecological cancer. J Sex Med. 2012;9(4):1162-1173.

42. Pitkin RM, Bradbury JT. The effect of topical estrogen on irradiated vaginal epithelium. Am J Obstet Gynecol. 1965;92:175-182.

43. Pitkin RM, VanVoorhis LW. Postirradiation vaginitis. An evaluation of prophylaxis with topical estrogen. Radiology. 1971;99(2):417-421.

44. Hintz BL, Kagan AR, Gilbert HA, Rao AR, Chan P, Nussbaum H. Systemic absorption of conjugated estrogenic cream by the irradiated vagina. Gynecol Oncol. 1981;12(1):75-82.

45. Poma PA. Postirradiation vaginal occlusion: nonoperative management. Int J Gynaecol Obstet. 1980;18(2):90-92.

46. Galuppi A, Perrone AM, La Macchia M, et al. Local alpha-tocopherol for acute and short-term vaginal toxicity prevention in patients treated with radiotherapy for gynecologic tumors. Int J Gynecol Cancer. 2011; 21(9):1708-1711.

47. Mohamed S, Lindegaard JC, de Leeuw AA, et al. Vaginal dose deescalation in image guided adaptive brachytherapy for locally advanced cervical cancer. Radiother Oncol. 2016;120(3):480-485.

48. Zavitsanos PJ, Leonard KL. Patterns of care in women with highintermediate risk endometrioid adenocarcinoma in the PORTEC-2 era: a SEER database analysis. Brachytherapy. 2017;16(1):109-115.

49. Thomas GM. A role for adjuvant radiation in clinically early carcinoma of the endometrium? Int J Gynecol Cancer. 2010;20(11 Suppl 2): S64-S66. 
International Journal of Women's Health

Dovepress

\section{Publish your work in this journal}

The International Journal of Women's Health is an international, peerreviewed open-access journal publishing original research, reports, editorials, reviews and commentaries on all aspects of women's healthcare including gynecology, obstetrics, and breast cancer. The manuscript management system is completely online and includes Visit http://www.dovepress.com/testimonials.php to read real quotes from published authors.

Submit your manuscript here: http://www.dovepress.com/international-journal-of-womens-health-journal 